Tropical Journal of Pharmaceutical Research September 2015; 14 (9): 1605-1611

ISSN: 1596-5996 (print); 1596-9827 (electronic)

(C) Pharmacotherapy Group, Faculty of Pharmacy, University of Benin, Benin City, 300001 Nigeria.

All rights reserved.

Available online at http://www.tjpr.org

Original Research Article

http://dx.doi.org/10.4314/tjpr.v14i9.9

\title{
Characterization of Polyhydroxyalkanoates Produced by Contaminated Soil Bacteria using Wastewater and Glucose as Carbon Sources
}

\author{
Sajida Munir* and Nazia Jamil \\ Department of Microbiology and Molecular Genetics, University of the Punjab, Lahore-54590, Pakistan
}

*For correspondence: Email: sajidamunir1@yahoo.com.au; Tel: +92-332-418-4278

Received: 10 May 2015

Revised accepted: 9 August 2015

\begin{abstract}
Purpose: To isolate polyhydroxyalkanoates (PHA)-producing bacterial strains from contaminated soil using industrial wastewater and glucose as carbon sources.

Methods: The strains were isolated and identified as Pseudomonas, Bacillus, Enterobacter, Exiguobacterium and Stenotrophomonas using biochemical tests and further confirmed by Macrogen sequencing. Two different sources, namely, glucose and wastewater were used to evaluate and compare the use of wastewater as a carbon source for PHA production. The biomass obtained was analyzed by Fourier transform infra-red (FTIR) to identify the presence of PHA in it. Afterwards, PHA extraction was carried out and then gas chromatography $(G C)$ performed to identify PHA monomers.

Results: Utilization of glucose resulted in the production of PHB, while wastewater yielded copolymers poly-3 hydroxybutyrate-co-3hydroxyvalerate $P(3 H B-c o-3 H V)$ due to its content of volatile fatty acids such as acetic acid, propionic acid and butyric acid, which led to the production of different types of polymers. The maximum PHA production was $41 \pm 0.22 \%$ obtained for Stenotrophomonas (SM03) using $2 \%$ glucose as carbon source while for wastewater, maximum production was achieved by the Pseudomonas strain (SM01).

Conclusion: Wastewater is produced in large quantities daily during various activities and therefore can be used as a cheap carbon source for the production of valuable products such as PHA.
\end{abstract}

Keywords: Polyhydroxyalkanoates, Wastewater, Glucose, Pseudomonas strain, Stenotrophomonas

Tropical Journal of Pharmaceutical Research is indexed by Science Citation Index (SciSearch), Scopus, International Pharmaceutical Abstract, Chemical Abstracts, Embase, Index Copernicus, EBSCO, African Index Medicus, JournalSeek, Journal Citation Reports/Science Edition, Directory of Open Access Journals (DOAJ), African Journal Online, Bioline International, Open-J-Gate and Pharmacy Abstracts

\section{INTRODUCTION}

Polyhydroxyalkanoates (PHA), produced by around 300 different bacterial strains, serve as carbon and energy storage material and are similar to synthetic plastics in physical and chemical properties. Therefore, they are considered to be a good alternative to petrochemical plastics [1].

PHA production in industries is carried out using pure microbial cultures, the maintenance of which is the main component of the high cost of
PHA production. This contributes to the high cost of pure-culture PHA relative to conventional plastics [2,3]. Efforts have been made in recent decades to discover ways to achieve low-cost production of PHA. The use of mixed microbial cultures in sludge or wastewater is one of such approaches as it eliminates the need for media and equipment sterilization $[4,5]$.

Industrial wastewater, which is highly loaded with organic materials, has been investigated as a carbon substrate for producing PHA because it showed good results in initial experiments [6]. In 
this context, several types of waste effluents were used to determine their ability for PHA production such as sugar industry, oil industry paper or municipal waste. Although the PHA production capacity obtained by these substrates was not as high as obtained with synthetic substrates, a reasonably high capacity of up to $55 \%$ PHA of the cell dry weight could be achieved [7-9]. The highest PHA per cell dry weight was obtained with wastewater by Albuquerque et al [10] and it amounted to about $75 \%$. Nonetheless, the process still needs to be improved and optimized for higher yield of PHA from wastewater effluents. Wastewater is composed of many carbon substrates that are easily biodegraded and converted to PHAs by bacteria instead of utilizing it for the formation of bacterial cell components [11].

Wastewater is composed of a lot of substrates along with acetate and experiments were conducted using different compounds separately or in mixtures that includes propionate, butyrate, glucose, lactate but the metabolism of these organic substrates is not yet well understood [12].

The ability of the bacterial strains to produce PHA using glucose and wastewater as carbon sources was analyzed in this work. The purpose of the study was to evaluate the ability of the bacteria to produce valuable products by using raw substrates such as wastewater in comparison with synthetic feedstock and then checking the produced polymers for their monomer composition.

\section{EXPERIMENTAL}

\section{Wastewater preparation and analysis}

Industrial wastewater used as a growth media was collected from Hadiara drain, Ferozpur road, Lahore, Pakistan and kept at $-18^{\circ} \mathrm{C}$ before use until required. Its $\mathrm{pH}$ was also measured with a $\mathrm{pH}$ meter. To use it as a media heating of wastewater was done to remove the insoluble solid particles then followed by centrifugation at $4000 \mathrm{rpm}$ for $10 \mathrm{~min}$. This clarified wastewater was autoclaved at $121^{\circ} \mathrm{C}$ for $15 \mathrm{~min}$ [13] and used in different concentrations. Wastewater was analyzed for different components present in it by using APHA standard methods for analysis of water and wastewater [14].

\section{PHA producing strains}

Bacterial strains were isolated from contaminated soil near industrial wastewater drain and were purified on $\mathrm{N}$-agar plates. Soil sample was added into a 125-mL Erlenmeyer flasks containing 20 $\mathrm{mL}$ nutrient broth composed of $(\mathrm{g} / \mathrm{L})$ : beef extract, 3.0 and tryptone, 5.0, and incubation was done on a rotary shaker at $37^{\circ} \mathrm{C}$ and $150 \mathrm{rpm}$ for $24 \mathrm{~h}$ after incubation, $0.1 \mathrm{~mL}$ of the sample was taken out and plated on nutrient agar plates and incubated at $37^{\circ} \mathrm{C}$ for $24 \mathrm{~h}$. Morphological and biochemical characterization was undertaken and bacterial genus was identified. Sudan Black $B$ staining was used to confirm PHA producing strains [15]. Heat fixed film of bacterial strains were prepared on a slide and Sudan black B staining was carried out for $15 \mathrm{~min}$. PHA detection agar (PDA) media containing $5 \mu \mathrm{L} / \mathrm{mL}$ Nile blue $A$ was used for the direct screening of PHA producers [16]. Plates were incubated at 37 ${ }^{\circ} \mathrm{C}$ for $24 \mathrm{~h}$. PHA producers show fluorescence when the plates were illuminated with UV light and hence are detected. Five strains were selected for further experimentation named as SM01, SM02, SM03, SM04, and SM05. Genomic DNA was isolated by miniprep method [17] and used as template in $\mathrm{PCR}$ reaction using thermocycle Primus96 (PeQLab) for the detection and isolation of $16 \mathrm{~S}$ rRNA. The isolated DNA fragments were sent to Macrogen, Korea for the identification of the strains. Phylogenetic analysis of the strains was identified using MEGA 6.0 software.

\section{Seed culture media preparation}

Seed culture media was prepared containing $\mathrm{g} / \mathrm{L}$; $\mathrm{Na}_{2} \mathrm{HPO}_{4}$ 6.36, $\mathrm{KH}_{2} \mathrm{PO}_{4}$ 2.7, $\left(\mathrm{NH}_{4}\right)_{2} \mathrm{SO}_{4}$ 4.70, $\mathrm{MgSO}_{4}$ 0.39, N-Broth 1, Glucose 9. Trace element solution $1 \mathrm{~mL} / \mathrm{L}$ was added, $(\mathrm{g} / \mathrm{L}$, $\mathrm{FeSO}_{4} .7 \mathrm{H}_{2} \mathrm{O} 10, \mathrm{ZnSO}_{4} .7 \mathrm{H}_{2} \mathrm{O} 2.25, \mathrm{CuSO}_{4} .5 \mathrm{H}_{2} \mathrm{O}$ 1, $\mathrm{MnSO}_{4} .5 \mathrm{H}_{2} \mathrm{O} \quad 0.5, \quad \mathrm{CaCl}_{2} .2 \mathrm{H}_{2} \mathrm{O}$ 2.0, $\mathrm{Na}_{2} \mathrm{~B}_{4} \mathrm{O}_{7} .10 \mathrm{H}_{2} \mathrm{O}$ 0.23, $\left(\mathrm{NH}_{4}\right)_{6} \mathrm{Mo}_{7} \mathrm{O}_{24} 0.1,35 \%$ $\mathrm{HCl} 10 \mathrm{~mL}$ ). $\mathrm{pH}$ was kept at 7.0 for the growth of isolates. The inoculum was prepared in $50 \mathrm{~mL}$ flasks and incubated at $37{ }^{\circ} \mathrm{C}$ for $24 \mathrm{~h}$ at 150 rpm.

\section{Production of PHA using glucose as substrate}

PHA screening media was prepared with the following composition ( $\mathrm{g} / \mathrm{L} ; \mathrm{Na}_{2} \mathrm{HPO}_{4}$ 6.36, $\mathrm{KH}_{2} \mathrm{PO}_{4}$ 2.7, $\left(\mathrm{NH}_{4}\right)_{2} \mathrm{SO}_{4} 0.50, \mathrm{MgSO}_{4} 0.39$, and 1 $\mathrm{mL} / \mathrm{L}$ of trace element solution). Glucose was added at 1, 2 and $3 \%$ concentration and the $\mathrm{pH}$ of the medium was adjusted at 7.0. Inoculum (2 $\%)$ from seed culture media was transferred to screening medium and incubation was carried out in a shaker at $37^{\circ} \mathrm{C}$ and $150 \mathrm{rpm}$. Sample $(10 \mathrm{~mL})$ was collected after every $24 \mathrm{~h}$ until $96 \mathrm{~h}$ to measure cell dry weight (CDW) and PHA content. 


\section{Production of PHA using bioindustrial wastewater}

PHA screening media was prepared as mentioned above but instead of glucose wastewater was used as a carbon source. Different concentrations of wastewater were used to check the ability for PHA production i.e; $20,40,60,80$ and $100 \%$. pH was adjusted to 7.0. Inoculum (2\%) from seed culture was given to the medium and incubated at $37{ }^{\circ} \mathrm{C}$ and 150 rpm. Sample $(10 \mathrm{~mL})$ was taken after every $24 \mathrm{~h}$ until $96 \mathrm{~h}$ to measure cell dry weight (CDW) and PHA content.

\section{Determination of cell dry weight}

Samples $(10 \mathrm{~mL})$ from the culture media were taken at regular time intervals and centrifugation was done at $4,000 \mathrm{rpm}$ for $15 \mathrm{~min}$. supernatant was discarded and pellet collected at the bottom was washed using distilled water and pellet was lyophilized to dry it and then weighed. The pellet samples were stored at room temperature in a dry location until PHA extraction was carried out.

\section{Determination of PHA}

PHA in the biomass was determined by examining the dried biomass on the ATR-FTIR. The scanning conditions were spectral range between $4000 \mathrm{~cm}^{-1}$ and $400 \mathrm{~cm}^{-1}, 24-32$ scans, at a resolution of $4 \mathrm{~cm}^{-1}$. The specific bands for PHA were observed in the biomass, so it was taken for PHA extraction.

\section{PHA extraction}

Biomass (8 grams) was treated with $100 \mathrm{~mL}$ sodium hypochlorite and $100 \mathrm{~mL}$ chloroform. The stored pellet of the cells was suspended using 35 $\%$ sodium hypochlorite to lyse the cells [15] and stop bacterial activity. Following this, chloroform was added and the mixture was incubated for one and half hour at $37{ }^{\circ} \mathrm{C}$ with constant shaking in a shaking incubator. After incubation, the solution was centrifuged at $4000 \mathrm{rpm}$ for $10 \mathrm{~min}$. Three layers were obtained after centrifugation, with the upper layer consisting of sodium hypochlorite, the central layer of cell debris and the bottom layer of a PHA-chloroform solution. This bottom layer was separated and solvent was allowed to evaporate.

\section{Gas chromatography}

Extracted PHA was analyzed for its chemical structure. For this purpose, about $8 \mathrm{mg}$ of purified PHA obtained after extraction was methanolyzed by adding $1 \mathrm{~mL}$ acidified methanol and $1.0 \mathrm{~mL}$ chloroform and heating was carried out at $100{ }^{\circ} \mathrm{C}$ for $140 \mathrm{~min}$. Sample $(1.0 \mu \mathrm{L})$ was injected using split injection method and nitrogen was used as the carrier gas at a flow rate of 3 $\mathrm{mLmin}^{-1}$. Polyhydroxybutyrate-hydroxyvalerate (PHBV, $30 \%$ ) was used as a standard to determine the respective retention times for monomer identification [18].

\section{RESULTS}

\section{Identification of bacterial strains}

Bacterial strains after isolation and purification on $\mathrm{N}$-agar plates were subjected to Sudan Black B staining. Black granules were observed in the cells under light microscope. With Nile Blue A dye, few of the strains showed fluorescence when exposed to UV light after $24 \mathrm{hrs}$ period. The microorganisms were identified using biochemical tests and then 16S rRNA fragments were submitted to Macrogen for sequencing. The strains belonged to genus Pseudomonas SM01 (KF270348), Bacillus SM02 (KF270351), Stenotrophomonas SM03 (KM234128), Exiguobacterium SM04 (KF928335) and Enterobacter SM05 (JF901811). The phylogenetic relationship and distances among the strains is shown in Figure 1.

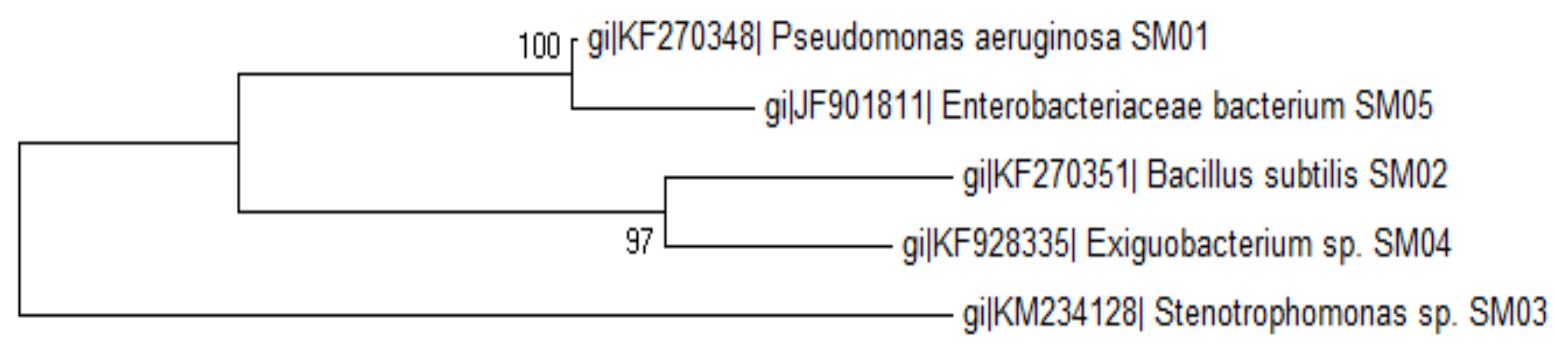

0.5

Fig 1: Phylogenetic tree for the sequenced strains 


\section{Wastewater analysis}

Table 1: Wastewater composition used in this study

\begin{tabular}{lc}
\hline Parameter & $\begin{array}{c}\text { Concentration } \\
(\mathbf{m g} / \mathbf{L})\end{array}$ \\
\hline COD & 61.0 \\
Magnesium & 22.0 \\
Nitrate & 1.26 \\
Nitrite & $\mathrm{N} . \mathrm{D}$ \\
Copper & 0.069 \\
Iron & 0.82 \\
Zinc & 0.36 \\
Manganese & 0.035 \\
Sodium & 171.0 \\
Potassium & 04 \\
Total sugars & 5500 \\
Phosphorus & 1.0 \\
Protein & 0.87 \\
Total Kjeldhal & \\
nitrogen & 4 \\
\hline
\end{tabular}

Industrial wastewater was analyzed for its different components using standard methods for analysis of water and wastewater [14]. The composition indicates that the water is composed of many components such as carbohydrates, proteins, nitrates and trace elements in minor amount as indicated by the data as given in Table 1. Due to this composition, the wastewater proved as a good carbon source for the bacterial strains and helped them to accumulate PHA up to $45 \%$ of cell dry weight.

\section{Assessment of growth in different carbon sources}

Three different concentrations 1, 2, and $3 \%$ of glucose were used in this study to evaluate the usage by different bacterial strains. The highest PHA content observed was $41 \pm 0.22 \%$ after 48 $h$ at $2 \%$ glucose concentration for strain SM03 as indicated by Figure $2 \mathrm{~b}$.

When wastewater was used as a carbon source in different concentrations, the maximum PHA obtained was $45 \pm 0.15 \%$ at $100 \%$ concentration of wastewater after $48 \mathrm{~h}$ incubation with the strains SM01 as shown in Figure 3b.
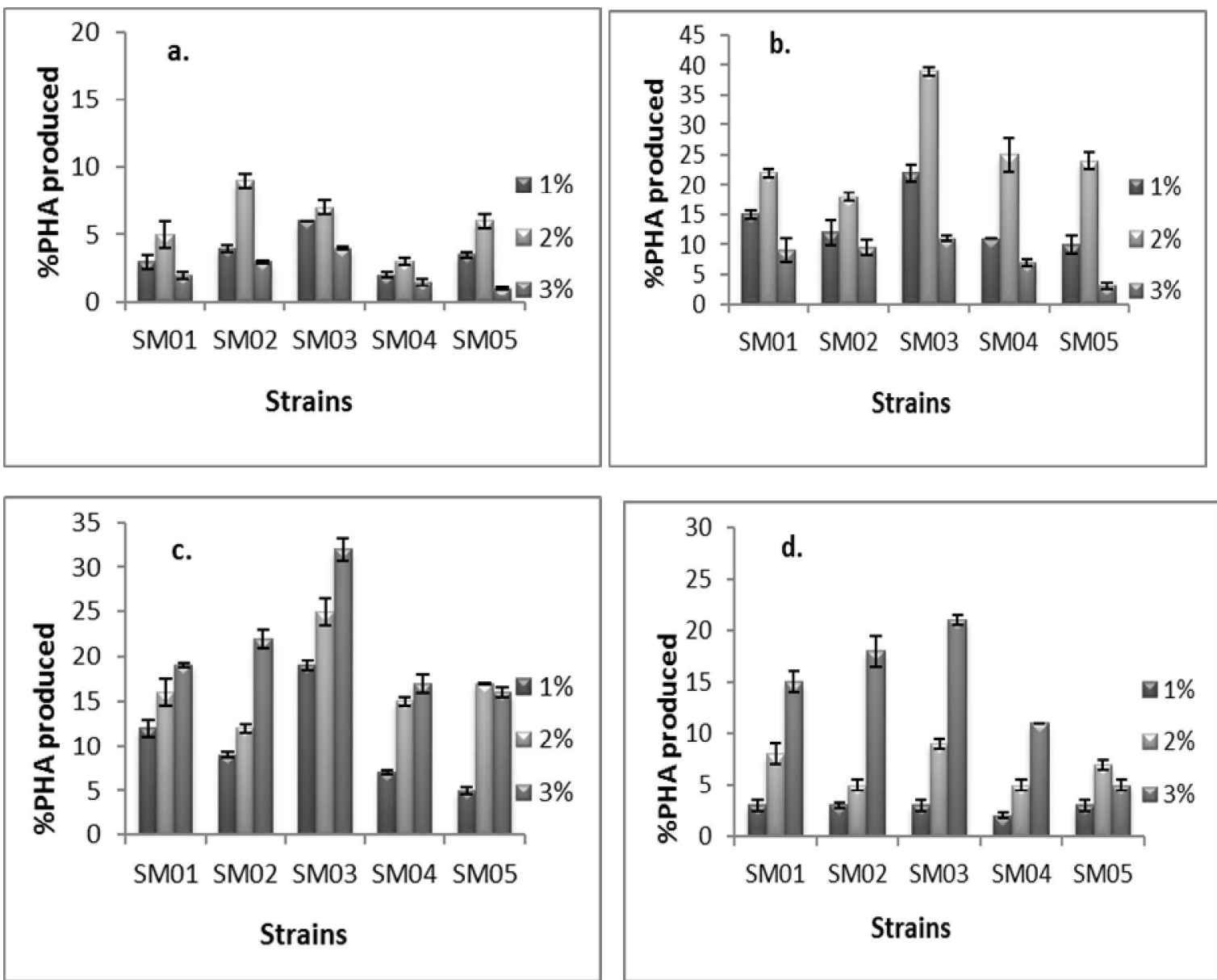

Fig 2: PHA production by bacteria at various concentrations of glucose; (a). after $24 \mathrm{~h}$, (b). after $48 \mathrm{~h}$, (c). after 72 $\mathrm{h}$, and (d) after $96 \mathrm{~h}$ 

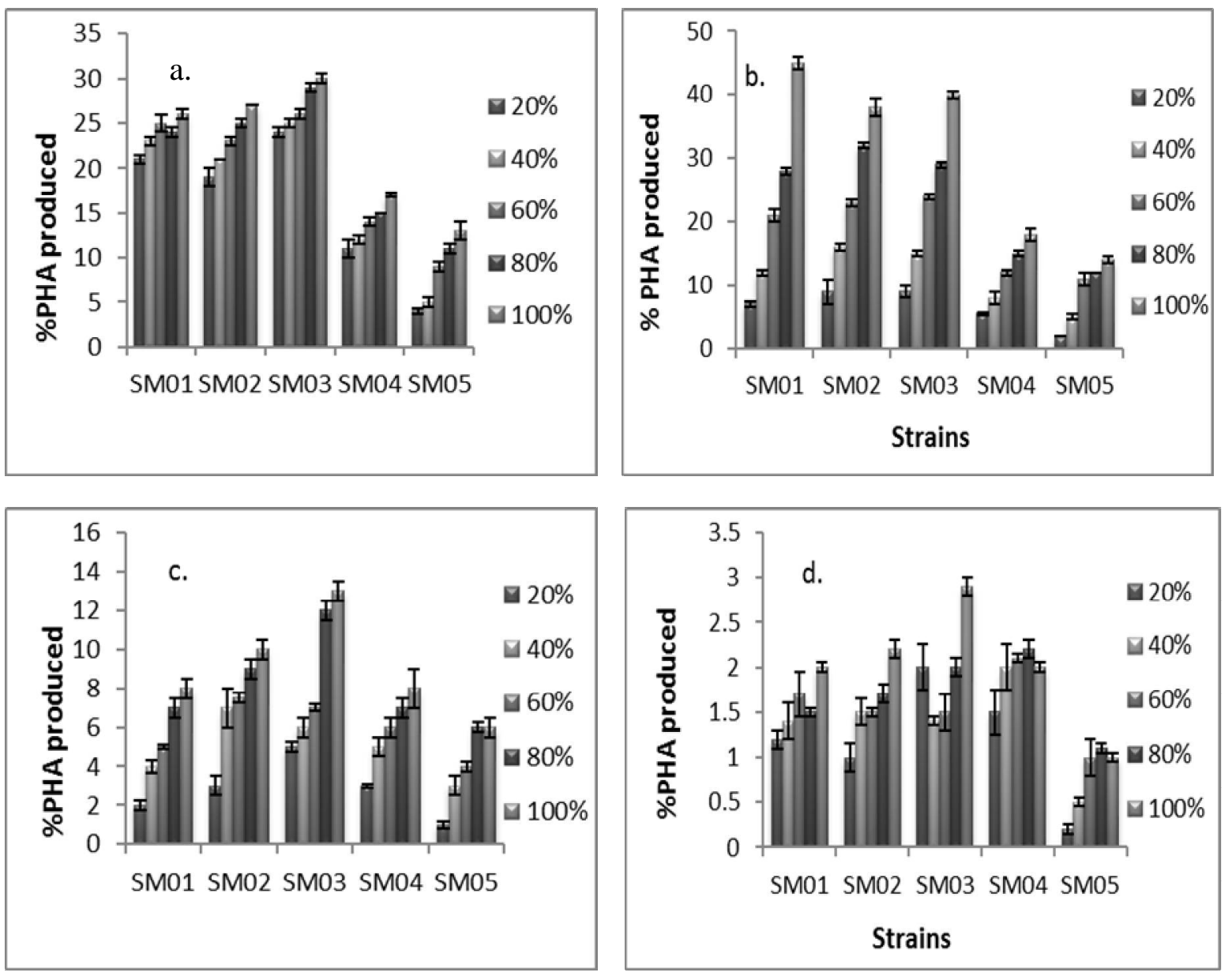

Fig 3: PHA production by bacteria at different concentrations of wastewater; (a). after $24 \mathrm{~h}$, (b). after 48 h, (c). after $72 \mathrm{~h}$, and (d) after $96 \mathrm{~h}$

\section{FTIR and GC}

When biomass was tested for presence of PHA, the bands were observed at $1730-1740 \mathrm{~cm}^{-1}$. According to Jarute et al [19] and Kansiz et al [20] the FTIR spectra peaks at about $1730 \mathrm{~cm}^{-1}$, and $1200 \mathrm{~cm}^{-1}$ to $900 \mathrm{~cm}^{-1}$ are considered as of PHA in pure cultures. The bands in the spectra which are regarded as PHA and other molecules such as cellular protein can be clearly distinguished from each other. With the help of $\mathrm{GC}$, the PHA content was identified as either HB or HV. In case of glucose as a carbon source, bacteria produced $3 \mathrm{PHB}$ while copolymers were produced in case of wastewater such as $\mathrm{P}(3 \mathrm{HB}-$ co-3HV).

\section{DISCUSSION}

Production of PHA at industrial level is limited due to its high production cost. The major hurdle is due to the availability of proper and cheap substrate. Therefore previous studies on production of PHA have focused to find suitable strategies for culture and media formulation. In this work, industrial wastewater and glucose were used to check the efficiency of the strains to produce PHA. We mainly focused at optimizing the polymer production with respect to substrate utilization with different concentrations. Results showed that wastewater sample is loaded with different nutrients as shown in Table 1 which helped the strains to survive and produce polyhydroxyalkanoates. Raw wastewater produced by industries and domestic uses is considered to be composed of organic material major part of which consists of organic carbon and also contains some compounds that are synthetic in nature and non-biodegradable [25].

The results for different strains with glucose showed that biomass increased till $48 \mathrm{~h}$ when the glucose was in abundance and there was less amount of PHA produced. Glucose was used efficiently at $2 \%$ concentration and after $48 \mathrm{~h}$, the biomass production was not increasing but the strains tend to accumulate PHA. The highest PHA (41.00 $\pm 0.22 \%)$ obtained for strain SM03 indicates that this organism has the potential to use glucose more efficiently as compared to other strains and the environment from which it 
was isolated seems to contain carbohydrates present in the industrial effluents. This leads to the conclusion that when most of the glucose was consumed, the bacteria was in stress condition which enhanced the storage of limited substrate available into PHA granules as described previously $[26,27]$. In case of $1 \%$ glucose, the glucose was consumed within $24 \mathrm{~h}$ and accordingly no significant PHA production was observed after that. In case of $3 \%$ glucose, the biomass and PHA production was slow due to high carbon load in the media.

When wastewater was used as a substrate for PHA production, all the strains showed growth and PHA production. Initially biomass production increased up to $24 \mathrm{~h}$ on $20 \%$ concentration, following which an increase in PHA content was observed. At 40, 60, 80 and $100 \%$ concentration of wastewater biomass increased until $48 \mathrm{~h}$, after which bacteria began to accumulate PHA. The maximum PHA production was observed with $100 \%$ wastewater by strain SM01 (Pseudomonas) up to $45.00 \pm 0.32 \%$ PHA of CDW as indicated by the Figure 2, indicating that there is much amount of carbon available for the bacteria [26].

The gas chromatography results indicated that there are PHB granules produced by the bacteria with glucose as a carbon source. In the case of wastewater, a random copolymer of $\mathrm{HB}$ and $\mathrm{HV}$ units was confirmed by $\mathrm{GC}$. The reason is that wastewater contains organic acids such as acetate, propionate, and butyrate which convert into copolymers with varying properties. Based on these results, it can be assumed that mixing of different types of carbon sources can lead to the production of biopolymers with desirable properties.

This indicates that mixed culture PHA production from wastewater may be a profitable avenue for the development of low cost, biodegradable polymers. Highly loaded wastewater reservoirs can potentially be further exploited for better PHA recovery and different types of polymers.

\section{CONCLUSION}

Using glucose and wastewater as carbon sources for PHA production is feasible. Utilization of wastewater will not only reduce pollution load of the environment but also lead to the production of polymers that have industrial importance. Various environmental wastes should be investigated to determine their suitability for the production of PHA and reducing its cost of production.

\section{ACKNOWLEDGEMENT}

The authors would like to thank the University of the Punjab, Lahore and Higher Education Commission of Pakistan.

\section{REFERENCES}

1. Verlinden RAJ, Hill $D J$, Kenward MA, Williams $C D$, Radecka I. Bacterial synthesis of biodegradable polyhydroxyalkanoates. J Appl Microbiol 2007; 102: 1437-1449.

2. Reis MAM, Serafim LS, Lemos PC, Ramos AM, Aguiar FR, Van Loosdrecht MCM. Production of polyhydroxyalkanoates by mixed microbial cultures. Bioprocess Biosyst Eng 2003; 25: 377-385.

3. Gurieff N, Lant P. Comparative life cycle assessment and financial analysis of mixed culture polyhydroxyalkanoate production. Bioresour Technol 2007; 98: 3393-3403.

4. Dionisi D, Majone M, Papa V, Beccari M. Biodegradable polymers from organic acids by using activated sludge enriched by aerobic periodic feeding. Biotechnol Bioeng 2004; 85: 569-579.

5. Reis $M$, Albuquerque $M$, Villano $M$, Majone M. Mixed culture processes for polyhydroxyalkanoate production from agro-industrial surplus wastes as feedstocks. Comprehensive Biotechnology, Academic Press, Burlington, Canada 2011; 669-683.

6. Albuquerque MGE, Eiroa $M$, Torres $C$, Nunes BR Reis MAM. Strategies for the development of a side stream process for polyhydroxyalkanoate (PHA) production from sugar cane molasses. J Biotechnol 2007; 130: 411-421.

7. Albuquerque MGE, Martino V, Pollet E, Avérous L, Reis $M A M$. Mixed culture polyhydroxyalkanoate (PHA) production from volatile fatty acid (VFA)-rich streams: effect of substrate composition and feeding regime on PHA productivity, composition and properties. J Biotechnol 2011; 151: 66-76.

8. Coats ER, Loge FJ, Wolcott MP, Englund K, McDonald AG. Synthesis of polyhydroxyalkanoates in municipal wastewater treatment. Water Environ Res 2007; 79:2396-403.

9. Dionisi D, Carucci G, Papini MP, Riccardi C, Majone M, Carrasco F. Olive oil mill effluents as a feedstock for production of biodegradable polymers. Water Res 2005; 39: 2076-2084.

10. Albuquerque MGE, Torres C, Reis MAM. Polyhydroxyalkanoate (PHA) production by a mixed microbial culture using sugar molasses: effect of the influent substrate concentration on culture selection. Water Res 2010; 44: 3419-3433.

11. Beun JJ, Dircks K, Heijnen JJ, van Loosdrecht MCM. Polyhydroxybutyrate metabolism in dynamically fed mixed microbial cultures. Water Res 2002; 36:116780.

Trop J Pharm Res, September 2015; 14(9): 1610 
12. Wang ND, Peng J, Hill G. Biochemical model of glucose induced enhanced biological phosphorus removal under anaerobic condition. Water Res 2002; 36: 4958.

13. Nitschke M, Pastore GM. Production and properties of a surfactant obtained from Bacillus subtilis grown on cassava wastewater. Bioresour Technol 2006; 97: 336-341.

14. APHA. Standard methods for the examination of water and wastewater. American Public Health Association: Washington; 1998

15. Lee SP, Choi J. Polyhydroxyalkanoates: Biodegradable Polymer. Manual of Industrial Microbiology and Biotechnology, American Society of Microbiology, Washington DC, USA; 1999. p. 616-627.

16. Chaudhry WN, Jamil N, Ali I, Ayaz MH, Hasnain S. Screening for polyhydroxyalkanoate (PHA)-producing bacterial strains and comparison of PHA production from various inexpensive carbon sources. Ann Microbiol 2011; 61: 623-629.

17. Morin N, Vallaeys $T$, Hendrickx L, Natalie L, Wilmotte A. An efficient DNA isolation protocol for filamentous cyanobacteria of the genus Arthrospira. J Microbiol Methods 2010; 80: 48-154.

18. Sin MC, Gan SN, Annuar MSM, Tan IKP. Chain cleavage mechanism of palm kernel oil derived medium-chainlength poly(3-hydroxyalkanoates) during high temperature decomposition. Polym Degrad Stab 2011; 96: 1705-1710.

19. Jarute G, Kainz A, Schroll G, Baena JR, Lendl B. On-line determination of the intracellular poly(hydroxybutyric acid) content in transformed Escherichia coli and glucose during PHB production using stopped-flow attenuated total reflection FT-IR spectrometry. Anal Chem 2004; 76: 6353-6358.

20. Kansiz M, Domínguez-Vidal A, McNaughton D, Lendl B. Fourier-transform infrared (FTIR) spectroscopy for monitoring and determining the degree of crystallisation of polyhydroxyalkanoates (PHAs). Anal Bioanal Chem 2007; 388: 1207-1213.

21. Orts WJ, Nobes GAR, Kawada J, Nguyen S, Yu G, Ravenelle F. Poly (hydroxyalkanoates): biorefinery polymers with a whole range of applications. Can J Biochem 2008; 86: 628-640.

22. Thompson RC, Swan SH, Moore CJ, Vom SFS. Our plastic age. Philos Trans $R$ Soc Lond B Biol Sci 2009; 364: 1973-1976.

23. Castilho LR, Mitchell BDA, Freirec DMG. Production of polyhydroxyalkanoates (PHAs) from waste materials and by-products by submerged and solid-state fermentation. Bioresour Technol 2009; 100: 59966009.

24. Lemos PC, Serafim LS, Reis, MAM. Synthesis of polyhydroxyalkanoates from different short-chain fatty acids by mixed cultures submitted toaerobic dynamic feeding. J Biotechnol 2006; 122:226-238.

25. Mansour HB, Mechri B, Ayed-Ajmi Y, Ghedira K, Barillier $D$, Hammami M, Mosrati R, Chekir L. Treatment of olive mill wastewaters by Pseudomonas putida $m t-2$ : Toxicity assessment of the untreated and treated effluent. Environ Eng Sci 2011; 28: 835-841.

26. Hori K, Marsudi S, Unno H. Simultaneous production of polyhydroxyalkanoates and rhamnolipids by Pseudomonas aeruginosa. Biotechnol Bioeng 2002; 78: 699-707.

27. Koller $M$, Bona $R$, Chiellini E, Fernandes EG, Horvat $P$, Kutschera $C$, Hesse $P$, Braunneg $G$. Polyhydroxyalkanoate production from whey by Pseudomonas hydrogenovora. Bioresour Technol 2008; 99: 4854-4863.

28. Ceyhan N, Ozdemir G. Polyhydroxybutyrate (PHB) production from domestic wastewater using Enterobacter aerogenes 12Bi strain. Afr J Microbiol Res 2011; 5: 690-702. 